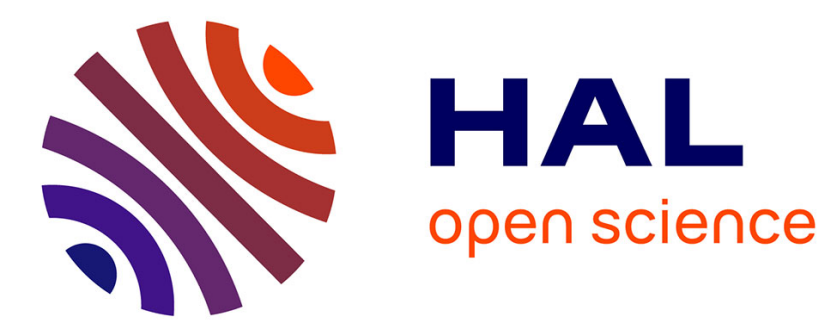

\title{
Osteoarthritis and type 2 diabetes mellitus: what are the links?
}

\author{
Alice Courties, Jérémie Sellam
}

\section{To cite this version:}

Alice Courties, Jérémie Sellam. Osteoarthritis and type 2 diabetes mellitus: what are the links?. Diabetes Research and Clinical Practice, 2016, 10.1016/j.diabres.2016.10.021 . hal-01396521

\section{HAL Id: hal-01396521 \\ https://hal.sorbonne-universite.fr/hal-01396521}

Submitted on 14 Nov 2016

HAL is a multi-disciplinary open access archive for the deposit and dissemination of scientific research documents, whether they are published or not. The documents may come from teaching and research institutions in France or abroad, or from public or private research centers.
L'archive ouverte pluridisciplinaire HAL, est destinée au dépôt et à la diffusion de documents scientifiques de niveau recherche, publiés ou non, émanant des établissements d'enseignement et de recherche français ou étrangers, des laboratoires publics ou privés. 


\section{Osteoarthritis and type 2 diabetes mellitus: what are the links?}

Alice Courties ${ }^{\mathrm{a}, \mathrm{b}}$, Jérémie Sellam ${ }^{\mathrm{a}, \mathrm{b}}$.

${ }^{\text {a }}$ Rheumatology Department, Saint-Antoine Hospital, Assistance Publique-Hôpitaux de Paris (AP-HP), DHU i2B, Paris, France

bInserm UMR S_938, Sorbonne Universités Univ Paris 06, DHU i2B, Paris, France

Correspondence to :

Prof. Jérémie Sellam

Hôpital Saint-Antoine

Service de Rhumatologie

184 rue du faubourg Saint-Antoine

75012 Paris

Tel: + 33149282520

Fax: + 33149282513

Jeremie.sellam@aphp.fr

Abstract words: 190

Word count: 3506

Number of pages: 19

Number of Tables/Figures: 3 


\begin{abstract}
Osteoarthritis (OA) is the most frequent joint disorder and one of the leading cause of disability. During a long time, it was considered as the consequence of aging and mechanical stress on cartilage. Recent advances in the knowledge of OA have highlighted that it is a whole joint disease with early modifications of synovium and subchondral bone but also that it is associated with obesity and metabolic syndrome through systemic mechanisms. In the past year, type 2 diabetes has been described in two meta-analyzes as an independent risk factor for OA. In vivo models of diabetes corroborated epidemiological studies. Indeed, diabetic rodents display a spontaneous and a more severe experimental OA than their nondiabetic counterparts, which can be partially prevented by diabetes treatment (insulin, pioglitazone). The negative impact of diabetes on joints could be explain by the induction of oxidative stress and pro-inflammatory cytokines but also by advanced age products accumulation in joint tissues exposed to chronic high glucose concentration. Insulin resistance might also impair joint tissue because of a local insulin resistance of diabetic synovial membrane but also by the systemic low grade inflammation state related to obesity and insulin resistant state.
\end{abstract}

Keywords: osteoarthritis, metabolic syndrome, diabetes mellitus, oxidative stress, glucose 


\section{Introduction}

Osteoarthritis (OA) is the most frequent musculoskeletal disease leading to joint pain, stiffness and disability. Worldwide estimates are that $9.6 \%$ of men and $18.0 \%$ of women aged $\geq 60$ years have symptomatic OA. It is expected to be the fourth cause of disability by 2020 and so it represents a public health challenge of the future years [1]. OA is a chronic joint disease targeting particularly lumbar spine, knee, hand and hip joints. It is characterized by a loss of cartilage associated with bone hypertrophy and sclerosis and with synovial inflammation. During a long time, ageing and mechanical stress were considered as the single risk factors. However, recent advances in the knowledge of OA has highlighted the involvement of other risk factors such as type 2 diabetes or dyslipidemia, currently included in the so-called metabolic syndrome (MetS), defining thus a new phenotype called metabolic OA, wider than obesity-related OA [2]. For some, obesity and metabolic syndrome increased the risk of knee and hip OA because of the related mechanical impact of overweight on those weight-bearing joints[3-5]. But, surprisingly, obesity or metabolic syndrome also increased the risk of hand OA [6-8] and, occurrence of metabolic disturbances associated with obesity aggravates the association between obesity and OA. Such new data opened to the idea that metabolic diseases could have a systemic influence on joint tissues, similarly to what happens for atherosclerosis. In this context, two recent meta-analyzes reported that type 2 diabetes was an OA risk factor, whatever the localization $[9,10]$. Moreover, during these last years, several in vitro and in vivo studies were published to decipher the influence of hyperglycemia and insulin resistance on joint tissues. High glucose exposure displays a local toxicity on joint tissue, increasing locally oxidative stress, cytokines, proteolytic enzymes production and advanced end glycation products (AGE) accumulation[11-13]. Furthermore, human synovial tissues from diabetic patients are insulin resistant and so potentially less responsive to the anti-inflammatory and anti-degradative effect of insulin[14]. Finally, in the field of metabolic 
syndrome, visceral obesity and insulin resistance are associated with a systemic low-grade inflammation state, which may also participate to OA development. In this review, we will develop the available evidence of an association between OA and diabetes, that could thus delineate sub-phenotype within the metabolic OA: the diabetes-induced OA.

\section{OA phenotypes classification}

Main OA risk factors are age, joint traumatism/injury, family history of OA corresponding to the genetic component, obesity and metabolic syndrome. They subsequently defined different phenotypes which are: OA related to ageing, post-traumatic OA, genetic OA and metabolic OA (Table 1) [2]. This classification is based on the fact that OA affects different population depending on the risk factors involved which, intuitively, may imply also different pathogenic pathways and, in the future, specific therapeutic management.

\section{Pathophysiology of OA: not only a cartilage disease but a "whole-joint" disease}

OA is a complex joint disease, affecting all joint tissues that are articular cartilage, subchondral bone and synovium. During a long time, it was considered as a "degenerative" and mechanical disease but $\mathrm{OA}$ is associated with a local and systemic low-grade inflammation state. The different risk factors are responsible for biological and/or mechanical aggressions, which influence the homeostasis of all tissues and cells.

Articular cartilage is composed of and extracellular matrix that contains a single type of cell: the chondrocyte - which is responsible for the synthesis of this extracellular matrix (anabolism). This matrix is mainly composed of water, proteoglycans and type 2 collagen. There is a low-grade turnover of components of this matrix due to catabolic activity of chondrocytes. One of the roles of cartilage is to absorb the mechanical stresses between 2 mobile bone surfaces. In OA, a biological or mechanical stress is followed by an increase of pro-inflammatory mediators production by chondrocytes (i.e., chondrocyte activation) but 
also by synoviocytes and osteoblasts, in each respective tissue. Among those proinflammatory mediators, cytokines (interleukin-1 $\beta$ (IL-1 $\beta$ ), IL-6, Il-17, Tumor necrosis factor- $\alpha$ (TNF- $\alpha)$ ), radical oxygen species (ROS), advanced glycation end products (AGE) and bio-active lipids (prostaglandine $\mathrm{E}_{2}\left(\mathrm{PGE}_{2}\right)$ ) are the most represented. This local inflammation induces an increase production of the proteolytic enzymes (metalloproteinase (MMP) and aggrecanases) by all 3 cells (i.e., chondrocytes, synoviocytes and osteoblasts) that will digest the cartilage matrix. In addition, chondrocytes dedifferentiate and die by apoptosis, leading to a synthesis of an altered matrix (type 10 instead of type 2 collagen) and to a loss of matrix synthesis respectively. While physiologically cartilage is non-vascularized, neoangiogenesis is promoted in the deep layer of cartilage facilitating the passage of soluble mediators between subchondral bone and cartilage by specific pro-angiogenic mediators and leads to the development of vascular channel. In addition to cartilage disruption, subchondral bone undergoes remodeling with condensation and overgrowth (osteophytes) under the influence of growth factors such as insulin-growth factor and transforming growth factor. Finally, synovium inflammation occurs in adjacent area of cartilage degradation due to cartilage debris. Infiltration of inflammatory cells such as lymphocytes and macrophages are responsible for overproduction of cytokines, oxidative stress and proteolytic enzymes which in turn aggravate cartilage degradation creating a vicious circle [15].

\section{Type 2 diabetes and OA: epidemiological association}

Association between diabetes mellitus and OA was first described in 1961[16]. Since then, considering all the published literature, the independent association between OA and type 2 diabetes is quite convincing. The $1^{\text {st }}$ large study with an accurate method exploring this association was from Schett et al. in 2007[17]. They demonstrated in a large population based-study that patients with type 2 diabetes had 2 times higher rates of knee or hip arthroplasty for OA- as a maker of OA severity- than non-diabetics. Beyond the number of 
subjects included (942 subjects) and the longitudinal follow-up of 20 years, the strength of this study was the numbers of confounders included such as age, low-grade inflammation (usCRP), body mass index (BMI) and other metabolic diseases, physical activity score or prior joint replacement. They also found that the risk of arthroplasty was correlated with type 2 disease duration and that type 2 diabetic patients had more inflammation of synovium (i.e., synovitis) and more pain. Eymard et al. found concordant results since they reported that type 2 diabetes patients had a higher rate of knee OA progression than non-diabetics on a 3 years follow up[18]. The association between OA and type 2 diabetes is also true for hand, especially for young patients. Indeed, 55-62 years old patients with type 2 diabetes had a 2 times higher rate of hand OA than non-diabetics and it seems to be associated with pain in erosive hand OA (i.e., a very destructive hand OA subtype) $[6,19]$.

Some other studies have focused on the glycaemia value and OA. During the 90's, Cimmino et al. found that the crude fasting plasma glucose level was higher in OA patients compared to non OA patients[20] and such a high level could be predictive of OA knee features using magnetic resonance imagery 10 years later[21]. However, a recent crosssectional study failed to find an association between Homeostasis Model Assessment of insulin resistance (HOMA-IR), HbA1c or insulin levels and OA in patients without glucoselowering drugs [22].

All these studies were recently included in two independent meta-analyzes. The first from our group found a greater risk of OA in type 2 diabetic with an odds ratio $(\mathrm{OR})=1.46(95 \%$ confidence interval (CI) :1.08 to 1.96) and a higher risk of diabetes in OA population with OR=1.41 (\%95CI: 1.21 to 1.65)[9]. However, studies included did not all adjusted for the weight, which may be a confounding factor. In the 12 studies adjusting for weight, 7 were positive meaning that weight could not explain exclusively its association. As well, Williams 
et al., found that the risk of $\mathrm{OA}$ in diabetic patients was higher compared to non-diabetic with an OR: 1.25 (95\% CI: 1.05 to 1.46) including only studies controlling for weight or BMI [10].

Those 2 meta-analyzes has been yet counterbalanced by two recent negative study. The first study from Nielen et al., explored the risk of total joint replacement (TJR) in a case-control studies (type 1 and type 2 diabetes versus non diabetic subjects) and found no association between diabetes and TJR. This may be biased to the fact that practitioners preferred the conservative treatment in diabetic patients because of their frailty which was illustrated by the fact that the risk of TJR decreased with increasing HbA1c levels [23]. The $2^{\text {nd }}$ study from Frey et al., did not find any association between type 2 diabetes, its duration or severity and incident hand OA[24]. However, it was based on a UK database with uncertainty of diagnoses and may have underestimated the number of $\mathrm{OA}$ and/or diabetic patients.

Surprisingly, the only data available on the specific association between type 1 diabetes and OA comes from an unpublished data of the 2016 Osteoarthritis research Society International Congress. This study reported no difference of radiographic hand OA prevalence between type 1 diabetes and age and sex-matched controls. However, patient with less controlled type 1 diabetes displayed higher hand pain[25]. The study of the specific association between type 1 diabetes and $\mathrm{OA}$ is of interest because it could evaluate the influence of diabetes in a population with hyperglycemia but without insulin resistance. Such a result needs to be further confirmed in other studies.

\section{Type 2 diabetes and OA: pathological association}

Type 2 diabetes has pathogenic effect through 2 major pathways. First, as for other organs, chronic hyperglycemia induces oxidative stress, overproduction of pro-inflammatory cytokines and AGEs in joint tissues but it also reduced the stem cells potential of 
differentiation. Second, the insulin resistance could play a role locally but also through the systemic low-grade inflammation state. We will discuss the effect of diabetes and glucose on the joint tissues and cells.

\subsection{Diabetes and cartilage :}

The major advances in the knowledge of the role of high glucose concentration on joint tissues involve mainly chondrocytes and cartilage. Cartilage is a non-vascularized and noninnervated tissue and receives nutrients from its connection with subchondral bone and synovial fluid through joint cavity. However, chondrocytes are glycolytic cells and express glucose transporters (GLUT), especially GLUT-1, GLUT-3 and GLUT-9[26] and are able to sense the glucose concentration in the media and to adapt the GLUT expression and membrane incorporation. Under glucose deprivation, normal chondrocytes increased GLUT-1 expression and membrane incorporation whereas they decreased under high glucose condition. This capacity of normal chondrocytes to adapt themselves to the local glucose level is lost during OA: this is responsible for a high glucose uptake and potential glucose toxicity [27]. Furthermore, GLUT expression is under the control of a number factors. Their expressions raised under pro-inflammatory stimuli as TNF-alpha and IL-1 $\beta$ through phosphokinase $\mathrm{C}$, but also under metabolic and hypoxic factors [28] which are involved and increased during OA.

The $1^{\text {st }}$ negative impact of local high glucose concentration is the reduction of the chondrogenic differentiation of mesenchymal [29] , muscle [30] and adipose-derived stem [31] cells which may further decrease the potential of regeneration of cartilage that is already decreased in OA. As well, adipose derived stem cells from diabetic patient had a spontaneous less chondrogenic differentiation potential than non-diabetic adipose stem cells. 
Furthermore, chronic high glucose environment has a noxious effect on chondrocytes metabolism. Human diabetic cartilages produce more IL-6 and $\mathrm{PGE}_{2}$ under IL1-beta stimulation than non-diabetic cartilage and displayed reduce autophagy and heme oxygenase expression, 2 anti-oxidant pathways[11,32,33]. As well, high glucose concentration sensitizes murine chondrocytes to IL-1 beta inducing a higher production of IL-6 and PGE 2 through oxidative stress compare to IL-1 beta in a normal glucose concentration. Aldose reductase and the polyol pathway seem also involved in this higher responsiveness. High glucose exposure also increases MMP production especially in human OA chondrocytes and decreases the production of collagen II. The pro-inflammatory and pro-degradative effect of high glucose on chondrocyte is partially inhibited by PPAR (peroxisome proliferator-activated receptors) gamma agonists[13,34] (Figure 2).

Advanced end glycation products (AGEs) may also participate to diabetes-induced OA. They are known to accumulate in cells and tissues under high glucose concentration. In vitro, AGEs induced a pro-inflammatory and pro-catabolic phenotype of chondrocytes via RAGE (receptor of AGE) and toll-like receptor. The activation of these receptors in chondrocytes induced a decrease of PPAR-gamma and an activation of Nf-kappa B and MAP kinase pathways [35-38]. AGEs accumulate with age in OA cartilage modifying its mechanical properties. However, only one in vivo studies showed that AGE accumulate in cartilage of diabetic streptozotocin (STZ) rats compared to non-diabetic rats [34] and further studies are needed to demonstrate the implication of AGE in diabetes-induced OA(Figure 2).

Several in vivo models have explored the role of diabetes on OA using type 1 (STZ models) or type 2 (high fat diet) diabetes models. In type 1 diabetic rats induced by STZ injection, Atayde et al. reported first that diabetes induces a spontaneous loss of proteoglycan in OA cartilage compare to non-diabetic rats despite a lower weight in diabetic group[39]. This was confirmed and reinforced by El Karib et al. study in which 8 weeks after STZ-diabetes 
induction, not only a loss of proteoglycan but a significant and spontaneous cartilage damage appeared compared to non-diabetic rat. This diabetes-induced OA could be prevented by insulin or by a mimicking agent called vanadium in type 1 diabetic rats [40]. As well, PPARgamma agonist (pioglitazone) has been shown to reduce the diabetes-induced OA in STZ diabetic mice leading also to a decrease of systemic inflammation (IL-6 and AGE)[34].

Using type 2 diabetic rat model, Onur et al. found that diabetic rats spontaneously developed OA[41]. However, in this model, type 2 diabetic rats had significant higher weight than non-diabetic, which is a bias. These results should be interpreted with caution even if Mooney et al. previously showed that, whatever the weight gain was, type 2 diabetes and obese mice had the same OA scores, probably because of the systemic metabolic disturbances and low-grade inflammation associated[42]. Finally, in an experimental and mechanical model of OA due to destabilization of medial meniscus in type 2 diabetic mice, rapamycin, a pharmacological activator of autophagy, prevented the diabetes-accelerated OA[43].

\subsection{Diabetes and synovium}

Less is known about hyperglycemia and synovium. High glucose concentration increases pro-angiogenic factors such as vascular endothelial growth factor (VEGF) expression in human synovial fibroblasts via oxidative stress, PI3K, Akt, c-Jun and AP-1 signaling pathways [44]. Synovial angiogenesis is known to induce pro-inflammatory cells locally. Some in vivo diabetic models discussed below have shown that diabetes induce more synovial inflammation especially in type 2 models than non-diabetic [43]. This is in the line with the clinical observation of more synovitis in knee OA in diabetic than in non-diabetic patients using ultrasound examination[17]. Such data have been recently corroborated by Hamada et al. who reported that the spontaneous OA of type 2 diabetes obese mice under high-fat diet was in part mediated by synovial overproduction of TNF- $\alpha$ in obese diabetic 
mice. Furthermore, they showed that human OA fibroblast like-synoviocytes (FLS) expressed insulin receptor and were responsive to insulin which was able to partially counteract the proinflammatory and pro-degradative effect of TNF $\alpha$. As insulin response was blunted in FLS from diabetic patients and TNF expression increased compared to non-diabetics, it could be possible that, because of their insulin resistant state, the FLS of diabetic patients are more sensitive to overproduce local TNF $\alpha$ a[14].

\subsection{Diabetes and subchondral bone}

Most of the studies on the relationship between bone and diabetes were published in the context of osteoporosis because diabetes is known to decrease bone remodeling. Specific study of subchondral bone and diabetes are rare. Fasting glucose concentration is associated with bone marrow lesions (BML) in knee joint in women using MRI [21]. These BML are known to predict OA structural damages[45]. In diabetic and hypertensive patients with advanced knee OA requiring arthroplasty, the loss of subchondral bone is increased depicted by a lower bone mineral density and a higher porosity, independently of weight[46]. Finally, AGE accumulate in subchondral bone of diabetic patients more than in non-diabetic which may impact the mechanical resistance of subchondral and display pro-inflammatory effects[47].

\subsection{Diabetes and joint tissues: systemic impact}

Insulin resistance and type 2 diabetes are most of the time the consequences of chronic visceral obesity and meta-inflammation that have been deeply explored [48]. Obesity is not only associated with knee or hip OA but also with hand OA, raising by 2 -fold the risk of hand OA[49]. As there is no mechanical link possible, it opens to the idea of a systemic association between obesity and OA. Several mechanisms have been developed in this field. First, visceral fat mass of obese patient is responsible for a higher production of cytokines, 
adipokines and acute phase reactant which play a major role in insulin resistancerelated[48,50,51]. As well, this chronic low-grade metabolic inflammation (i.e., metainflammation) could be one of the links between insulin resistance and OA. As we discuss below, inflammatory mediators are involved in OA pathophysiology. Griffin et al. developed mice models of obesity and insulin resistance using high fat diet and explored their systemic role on OA development. Under high fat diet, mice developed spontaneous OA which is inhibited in leptin deficient mice[52]. This demonstrated that the mechanical impact of weight in obesity-induced OA could not explain all the association. Leptin is one of the major adipokines, secreted mostly by adipose tissue. Its expression in cartilage increased with OA severity and its synovial rate is correlated with BMI [53]. In vitro, leptin is able to promote chondrocytes apoptosis but also to increase cytokines (IL-1 $\beta$ and IL-8)[53,54] or metalloproteinase [55] production by chondrocytes[56]. They also reported in an high fat diet model that exercise which do not permit a weight loss -but a decrease in glucose intolerance reduced $\mathrm{OA}$ progression, meaning that the insulin resistance state related to obesity is involved in joint damage[57].

Several adipokines has been also studies in the context of obesity and OA (for complete review see[58]). Indeed, resistin, visfatin (also called nicotinamide phosphoribosyltransferase Nampt) display pro-inflammatory and pro-catabolic effect in vitro on chondrocytes[59-63] while the role of adiponectin remains more controversial. In vivo, the local knee injection of visfatin inhibitor protected mice from mechanical OA[64]. However, no study has focused on adipokines as a link between $\mathrm{OA}$ and diabetes.

Along this line, insulin resistant state and obesity are also associated with elevated free fatty acids (FFA). The dietary content of FFA may modulate OA progression[65]. In vitro, palmitate has been shown to display pro-inflammatory effect on chondrocyte through 
oxidative stress and pro-apoptotic effect[66,67]. Interestingly, a protective effect of $n-3$ polyunsaturated acid rich diet and a pro-catabolic effect of n-6 polyunsaturated acid and saturated fatty acid diet was observed in joint mice[68].

Finally, as a new perspective and for now a very hypothetical theory, the role of microbiome in obesity and insulin resistance has emerged as a crucial actor in the pathophysiology of these 2 diseases and may be also involved in the metabolic OA. Indeed, OA patients have higher synovial and serum rate of lipopolysaccaharide (LPS) and LPS-binding protein (LBP) than non-OA patients. In high fat diet mice, modifications of microbiota correlate with OA severity[69,70]. These studies could be the emerging evidence of the involvement of microbiota in metabolic OA.

\section{Conclusion and perspectives:}

Epidemiological association between OA and type 2 diabetes is robust, beyond their common association with age or obesity. Type 2 diabetes is now considered as an additional risk factor of OA. Several mechanisms coming from in vivo and in vitro animal studies but also from studies of diabetic patients joint tissues support such an association. Diabetes may act on joint tissues through hyperglycemia and insulin resistance, notably through oxidative stress which is a therapeutic target in $\mathrm{OA}$ in general[71,72]. However, we do not know yet whether diabetes control and prevention can modulate OA occurrence and progression in humans. Such an issue needs to be explored for a better personalized care.

Funding: The present work was supported by the ROAD network (Fondation Arthritis Jacques Courtin). A.Courties was supported by the French Society of Rheumatology and the Assistance Publique des Hôpitaux de Paris (AP-HP).

Conflicts of interest: A.C : none, J.S : none. 
Table 1: OA phenotype classification and characteristics, adapted from Bijlsma et al[2].

\begin{tabular}{|c|c|c|c|c|}
\hline & Post-traumatic OA & OA -related to ageing & Genetic OA & Metabolic OA \\
\hline Patient age & Young (<45 years) & $\begin{array}{l}\text { Middle-Age } \quad(45-65 \\
\text { years) }\end{array}$ & Variable & Old (> 65 years) \\
\hline \multirow[t]{5}{*}{ Main causative factor } & Mechanical & AGE & Polymorphism - & Adipokines \\
\hline & & $\begin{array}{l}\text { Senescence associated } \\
\text { phenotype }\end{array}$ & Gene related factors & $\begin{array}{l}\text { Chronic mechanical } \\
\text { stress }\end{array}$ \\
\hline & & Oxidative stress & & Hyperglycemia \\
\hline & & Inflammaging & & Insulin resistance \\
\hline & & & & FFA and dyslipidemia \\
\hline Main localization & $\begin{array}{l}\text { Knee, Ankle, thumb, } \\
\text { Shoulder }\end{array}$ & Hand, knee, Hip & Hand, Hip, Spine & $\begin{array}{l}\text { Generalized, knee, } \\
\text { hand, spine }\end{array}$ \\
\hline
\end{tabular}

Abbreviations: AGE : Advanced End Glycation products; FFA: free fatty acids; OA : osteoarthritis.

Figure Legends:

Figure 1: Pathological joint features of osteoarthritis. Osteoarthritis is characterized by impairment of all joint tissues with osteophytes and sclerosis of subchondral bone, synovial membrane inflammation and cartilage degradation leading to cartilage debris in the joint cavity.

Figure 2: Diabetes-induced osteoarthritis (OA): involvement of hyperglycemia in local chondrocyte activation. 
High-glucose concentration induces advanced glycation end products (AGEs) formation in cartilage. AGEs interact with receptor of AGE (RAGE) and Toll-like receptor 4 to downstream peroxisome proliferator-activated receptor gamma (PPAR- $\gamma$ ), which induces oxidative stress (mitochondrial reactive oxygen species [mROS] and nitric oxide [NO]) and cytokine release by chondrocytes. AGEs also modify cartilage stiffness and resistance. Highglucose rate increases metalloprotease (MMP) expression and oxidative stress in chondrocytes but also synergizes the interleukin $1 \beta$ (IL-1 $\beta$ ) effect on cytokine release.

\section{References}

[1] Woolf AD, Pfleger B. Burden of major musculoskeletal conditions. Bull World Health Organ 2003;81:646-56.

[2] Bijlsma JWJ, Berenbaum F, Lafeber FPJG. Osteoarthritis: an update with relevance for clinical practice. Lancet 2011;377:2115-26. doi:10.1016/S0140-6736(11)60243-2.

[3] Puenpatom RA, Victor TW. Increased prevalence of metabolic syndrome in individuals with osteoarthritis: an analysis of NHANES III data. Postgrad Med 2009;121:9-20. doi:10.3810/pgm.2009.11.2073.

[4] Yoshimura N, Muraki S, Oka H, Tanaka S, Kawaguchi H, Nakamura K, et al. Accumulation of metabolic risk factors such as overweight, hypertension, dyslipidaemia, and impaired glucose tolerance raises the risk of occurrence and progression of knee osteoarthritis: a 3-year followup of the ROAD study. Osteoarthr Cartil 2012;20:1217-26. doi:10.1016/j.joca.2012.06.006.

[5] Monira Hussain S, Wang Y, Cicuttini FM, Simpson JA, Giles GG, Graves S, et al. Incidence of total knee and hip replacement for osteoarthritis in relation to the metabolic syndrome and its components: a prospective cohort study. Semin Arthritis Rheum 2014;43:429-36. doi:10.1016/j.semarthrit.2013.07.013.

[6] Dahaghin S, Bierma-Zeinstra SMA, Koes BW, Hazes JMW, Pols H a. P. Do metabolic factors add to the effect of overweight on hand osteoarthritis? The Rotterdam Study. Ann Rheum Dis 2007;66:916-20. doi:10.1136/ard.2005.045724.

[7] Visser AW, de Mutsert R, le Cessie S, den Heijer M, Rosendaal FR, Kloppenburg M, et al. The relative contribution of mechanical stress and systemic processes in different types of osteoarthritis: the NEO study. Ann Rheum Dis 2015;74:1842-7. doi:10.1136/annrheumdis2013-205012.

[8] Tomi A-L, Sellam J, Lacombe K, Fellahi S, Sebire M, Rey-Jouvin C, et al. Increased prevalence and severity of radiographic hand osteoarthritis in patients with HIV-1 infection associated with metabolic syndrome: data from the cross-sectional METAFIB-OA study. Ann Rheum Dis 2016. doi:10.1136/annrheumdis-2016-209262.

[9] Louati K, Vidal C, Berenbaum F, Sellam J. Association between diabetes mellitus and osteoarthritis: systematic literature review and meta-analysis. RMD Open 2015;1:e000077. doi:10.1136/rmdopen-2015-000077.

[10] Williams MF, London DA, Husni EM, Navaneethan S, Kashyap SR. Type 2 diabetes and osteoarthritis: a systematic review and meta-analysis. J Diabetes Complicat 2016;30:944-50. doi:10.1016/j.jdiacomp.2016.02.016.

[11] Laiguillon M-C, Courties A, Houard X, Auclair M, Sautet A, Capeau J, et al. Characterization of diabetic osteoarthritic cartilage and role of high glucose environment on chondrocyte 
activation: toward pathophysiological delineation of diabetes mellitus-related osteoarthritis. Osteoarthr Cartil 2015;23:1513-22. doi:10.1016/j.joca.2015.04.026.

[12] Oren TW, Botolin S, Williams A, Bucknell A, King KB. Arthroplasty in veterans: analysis of cartilage, bone, serum, and synovial fluid reveals differences and similarities in osteoarthritis with and without comorbid diabetes. J Rehabil Res Dev 2011;48:1195-210.

[13] Rosa SC, Rufino AT, Judas FM, Tenreiro CM, Lopes MC, Mendes AF. Role of glucose as a modulator of anabolic and catabolic gene expression in normal and osteoarthritic human chondrocytes. J Cell Biochem 2011;112:2813-24. doi:10.1002/jcb.23196.

[14] Hamada D, Maynard R, Schott E, Drinkwater CJ, Ketz JP, Kates SL, et al. Insulin Suppresses TNFdependent Early Osteoarthritic Changes Associated with Obesity and Type 2 Diabetes. Arthritis \& Rheumatology (Hoboken, NJ) 2015. doi:10.1002/art.39561.

[15] Sellam J, Berenbaum F. The role of synovitis in pathophysiology and clinical symptoms of osteoarthritis. Nat Rev Rheumatol 2010;6:625-35. doi:10.1038/nrrheum.2010.159.

[16] Waine H, Nevinny D, Rosenthal J, Joffe IB. Association of osteoarthritis and diabetes mellitus. Tufts Folia Med 1961;7:13-9.

[17] Schett G, Kleyer A, Perricone C, Sahinbegovic E, lagnocco A, Zwerina J, et al. Diabetes is an independent predictor for severe osteoarthritis: results from a longitudinal cohort study. Diabetes Care 2013;36:403-9. doi:10.2337/dc12-0924.

[18] Eymard F, Parsons C, Edwards MH, Petit-Dop F, Reginster J-Y, Bruyère O, et al. Diabetes is a risk factor for knee osteoarthritis progression. Osteoarthr Cartil 2015;23:851-9. doi:10.1016/j.joca.2015.01.013.

[19] Magnusson K, Hagen KB, Østerås N, Nordsletten L, Natvig B, Haugen IK. Diabetes is associated with increased hand pain in erosive hand osteoarthritis: data from a population-based study. Arthritis Care Res (Hoboken) 2015;67:187-95. doi:10.1002/acr.22460.

[20] Cimmino MA, Cutolo M. Plasma glucose concentration in symptomatic osteoarthritis: a clinical and epidemiological survey. Clin Exp Rheumatol 1990;8:251-7.

[21] Davies-Tuck ML, Wang Y, Wluka AE, Berry PA, Giles GG, English DR, et al. Increased fasting serum glucose concentration is associated with adverse knee structural changes in adults with no knee symptoms and diabetes. Maturitas 2012;72:373-8. doi:10.1016/j.maturitas.2012.05.013.

[22] Garessus EDG, de Mutsert R, Visser AW, Rosendaal FR, Kloppenburg M. No association between impaired glucose metabolism and osteoarthritis. Osteoarthr Cartil 2016;24:1541-7. doi:10.1016/j.joca.2016.04.007.

[23] Nielen JTH, Emans PJ, Dagnelie PC, Boonen A, Lalmohamed A, de Boer A, et al. Severity of Diabetes Mellitus and Total Hip or Knee Replacement: A Population-Based Case-Control Study. Medicine (Baltimore) 2016;95:e3739. doi:10.1097/MD.0000000000003739.

[24] Frey N, Hügle T, Jick SS, Meier CR, Spoendlin J. Type II diabetes mellitus and incident osteoarthritis of the hand: a population-based case-control analysis. Osteoarthr Cartil 2016;24:1535-40. doi:10.1016/j.joca.2016.04.005.

[25] Magnusson K, Juel NG, Brox JI, Holte K, Hagen KB, Haugen IK, et al. Long term type 1 diabetes is associated with hand pain but not with structural hand osteoarthritis features - The Dialong hand study. Osteoarthritis Cartilage n.d.;24:S209.

[26] Mobasheri A, Neama G, Bell S, Richardson S, Carter SD. Human articular chondrocytes express three facilitative glucose transporter isoforms: GLUT1, GLUT3 and GLUT9. Cell Biol Int 2002;26:297-300. doi:10.1006/cbir.2001.0850.

[27] Rosa SC, Gonçalves J, Judas F, Mobasheri A, Lopes C, Mendes AF. Impaired glucose transporter1 degradation and increased glucose transport and oxidative stress in response to high glucose in chondrocytes from osteoarthritic versus normal human cartilage. Arthritis Res Ther 2009;11:R80. doi:10.1186/ar2713.

[28] Shikhman AR, Brinson DC, Valbracht J, Lotz MK. Cytokine regulation of facilitated glucose transport in human articular chondrocytes. J Immunol 2001;167:7001-8. 
[29] Tsai T-L, Manner PA, Li W-J. Regulation of mesenchymal stem cell chondrogenesis by glucose through protein kinase C/transforming growth factor signaling. Osteoarthr Cartil 2013;21:36876. doi:10.1016/j.joca.2012.11.001.

[30] Aguiari P, Leo S, Zavan B, Vindigni V, Rimessi A, Bianchi K, et al. High glucose induces adipogenic differentiation of muscle-derived stem cells. Proc Natl Acad Sci USA 2008;105:1226-31. doi:10.1073/pnas.0711402105.

[31] Cramer C, Freisinger E, Jones RK, Slakey DP, Dupin CL, Newsome ER, et al. Persistent high glucose concentrations alter the regenerative potential of mesenchymal stem cells. Stem Cells Dev 2010;19:1875-84. doi:10.1089/scd.2010.0009.

[32] Ribeiro M, López de Figueroa P, Blanco FJ, Mendes AF, Caramés B. Insulin decreases autophagy and leads to cartilage degradation. Osteoarthr Cartil 2016;24:731-9. doi:10.1016/j.joca.2015.10.017.

[33] Vaamonde-Garcia C, Courties A, Pigenet A, Laiguillon M, Sautet A, Houard X, et al. Critical role of Nrf-2/HO-1 axis in the inflammatory feature of type 2 diabetes-associated osteoarthritis In preparation.

[34] Chen Y-J, Chan D-C, Lan K-C, Wang C-C, Chen C-M, Chao S-C, et al. PPARy is involved in the hyperglycemia-induced inflammatory responses and collagen degradation in human chondrocytes and diabetic mouse cartilages. J Orthop Res 2015;33:373-81. doi:10.1002/jor.22770.

[35] Wang J, Wang G, Sun GW. Role of PPAR $\alpha$ in down-regulating AGE-induced TGF- $\beta$ and MMP-9 expressions in chondrocytes. Genet Mol Res 2016;15. doi:10.4238/gmr.15027963.

[36] Chen YJ, Sheu ML, Tsai KS, Yang RS, Liu SH. Advanced glycation end products induce peroxisome proliferator-activated receptor $\gamma$ down-regulation-related inflammatory signals in human chondrocytes via Toll-like receptor-4 and receptor for advanced glycation end products. PLoS ONE 2013;8:e66611. doi:10.1371/journal.pone.0066611.

[37] Rasheed Z, Akhtar N, Haqqi TM. Advanced glycation end products induce the expression of interleukin- 6 and interleukin- 8 by receptor for advanced glycation end product-mediated activation of mitogen-activated protein kinases and nuclear factor-kB in human osteoarthritis chondrocytes. Rheumatology (Oxford) 2011;50:838-51. doi:10.1093/rheumatology/keq380.

[38] Rasheed Z, Haqqi TM. Endoplasmic reticulum stress induces the expression of COX-2 through activation of elF $2 \alpha, \mathrm{p} 38-\mathrm{MAPK}$ and NF-KB in advanced glycation end products stimulated human chondrocytes. Biochim Biophys Acta 2012;1823:2179-89. doi:10.1016/j.bbamcr.2012.08.021.

[39] Atayde SA, Yoshinari NH, Nascimento DP, Catanozi S, Andrade PC, Velosa APP, et al. Experimental diabetes modulates collagen remodelling of joints in rats. Histol Histopathol 2012;27:1471-9.

[40] El Karib AO, Al-Ani B, Al-Hashem F, Dallak M, Bin-Jaliah I, El-Gamal B, et al. Insulin and vanadium protect against osteoarthritis development secondary to diabetes mellitus in rats. Arch Physiol Biochem 2016;122:148-54. doi:10.3109/13813455.2016.1159698.

[41] Onur T, Wu R, Metz L, Dang A. Characterisation of osteoarthritis in a small animal model of type 2 diabetes mellitus. Bone Joint Res 2014;3:203-11. doi:10.1302/2046-3758.36.2000244.

[42] Mooney RA, Sampson ER, Lerea J, Rosier RN, Zuscik MJ. High-fat diet accelerates progression of osteoarthritis after meniscal/ligamentous injury. Arthritis Res Ther 2011;13:R198. doi:10.1186/ar3529.

[43] Ribeiro M, López de Figueroa P, Nogueira-Recalde U, Centeno A, Mendes AF, Blanco FJ, et al. Diabetes-accelerated experimental osteoarthritis is prevented by autophagy activation. Osteoarthr Cartil 2016. doi:10.1016/j.joca.2016.06.019.

[44] Tsai C-H, Chiang Y-C, Chen H-T, Huang P-H, Hsu H-C, Tang C-H. High glucose induces vascular endothelial growth factor production in human synovial fibroblasts through reactive oxygen species generation. Biochim Biophys Acta 2013;1830:2649-58. doi:10.1016/j.bbagen.2012.12.017. 
[45] Felson DT, McLaughlin S, Goggins J, LaValley MP, Gale ME, Totterman S, et al. Bone marrow edema and its relation to progression of knee osteoarthritis. Ann Intern Med 2003;139:330-6.

[46] Wen CY, Chen Y, Tang HL, Yan CH, Lu WW, Chiu KY. Bone loss at subchondral plate in knee osteoarthritis patients with hypertension and type 2 diabetes mellitus. Osteoarthr Cartil 2013;21:1716-23. doi:10.1016/j.joca.2013.06.027.

[47] Franke S, Rüster C, Pester J, Hofmann G, Oelzner P, Wolf G. Advanced glycation end products affect growth and function of osteoblasts. Clin Exp Rheumatol 2011;29:650-60.

[48] Hotamisligil GS, Shargill NS, Spiegelman BM. Adipose expression of tumor necrosis factor-alpha: direct role in obesity-linked insulin resistance. Science 1993;259:87-91.

[49] Yusuf E, Nelissen RG, Ioan-Facsinay A, Stojanovic-Susulic V, DeGroot J, van Osch G, et al. Association between weight or body mass index and hand osteoarthritis: a systematic review. Ann Rheum Dis 2010;69:761-5. doi:10.1136/ard.2008.106930.

[50] Hotamisligil GS, Arner P, Caro JF, Atkinson RL, Spiegelman BM. Increased adipose tissue expression of tumor necrosis factor-alpha in human obesity and insulin resistance. J Clin Invest 1995;95:2409-15. doi:10.1172/JCI117936.

[51] Gregor MF, Hotamisligil GS. Inflammatory mechanisms in obesity. Annu Rev Immunol 2011;29:415-45. doi:10.1146/annurev-immunol-031210-101322.

[52] Griffin TM, Huebner JL, Kraus VB, Guilak F. Extreme obesity due to impaired leptin signaling in mice does not cause knee osteoarthritis. Arthritis Rheum 2009;60:2935-44. doi:10.1002/art.24854.

[53] Simopoulou T, Malizos KN, Iliopoulos D, Stefanou N, Papatheodorou L, loannou M, et al. Differential expression of leptin and leptin's receptor isoform (Ob-Rb) mRNA between advanced and minimally affected osteoarthritic cartilage; effect on cartilage metabolism. Osteoarthr Cartil 2007;15:872-83. doi:10.1016/j.joca.2007.01.018.

[54] Gómez R, Scotece M, Conde J, Gómez-Reino JJ, Lago F, Gualillo O. Adiponectin and leptin increase IL-8 production in human chondrocytes. Ann Rheum Dis 2011;70:2052-4. doi:10.1136/ard.2010.145672.

[55] Hui W, Litherland GJ, Elias MS, Kitson GI, Cawston TE, Rowan AD, et al. Leptin produced by joint white adipose tissue induces cartilage degradation via upregulation and activation of matrix metalloproteinases. Ann Rheum Dis 2012;71:455-62. doi:10.1136/annrheumdis-2011-200372.

[56] Huang ZM, Du SH, Huang LG, Li JH, Xiao L, Tong P. Leptin promotes apoptosis and inhibits autophagy of chondrocytes through upregulating lysyl oxidase-like 3 during osteoarthritis pathogenesis. Osteoarthr Cartil 2016;24:1246-53. doi:10.1016/j.joca.2016.02.009.

[57] Griffin TM, Huebner JL, Kraus VB, Yan Z, Guilak F. Induction of osteoarthritis and metabolic inflammation by a very high-fat diet in mice: effects of short-term exercise. Arthritis Rheum 2012;64:443-53. doi:10.1002/art.33332.

[58] Courties A, Gualillo O, Berenbaum F, Sellam J. Metabolic stress-induced joint inflammation and osteoarthritis. Osteoarthr Cartil 2015;23:1955-65. doi:10.1016/j.joca.2015.05.016.

[59] Laiguillon M-C, Houard X, Bougault C, Gosset M, Nourissat G, Sautet A, et al. Expression and function of visfatin (Nampt), an adipokine-enzyme involved in inflammatory pathways of osteoarthritis. Arthritis Res Ther 2014;16:R38. doi:10.1186/ar4467.

[60] Tang C-H, Chiu Y-C, Tan T-W, Yang R-S, Fu W-M. Adiponectin enhances IL-6 production in human synovial fibroblast via an AdipoR1 receptor, AMPK, p38, and NF-kappa B pathway. J Immunol 2007;179:5483-92.

[61] Tong K-M, Chen C-P, Huang K-C, Shieh D-C, Cheng H-C, Tzeng C-Y, et al. Adiponectin increases MMP-3 expression in human chondrocytes through AdipoR1 signaling pathway. J Cell Biochem 2011;112:1431-40. doi:10.1002/jcb.23059.

[62] Zhang Z, Zhang Z, Kang Y, Hou C, Duan X, Sheng P, et al. Resistin stimulates expression of chemokine genes in chondrocytes via combinatorial regulation of C/EBP $\beta$ and NF-KB. Int J Mol Sci 2014;15:17242-55. doi:10.3390/ijms151017242.

[63] Zhang Z, Xing X, Hensley G, Chang L-W, Liao W, Abu-Amer Y, et al. Resistin induces expression of proinflammatory cytokines and chemokines in human articular chondrocytes via 
transcription and messenger RNA stabilization. Arthritis Rheum 2010;62:1993-2003. doi:10.1002/art.27473.

[64] Yang S, Ryu J-H, Oh H, Jeon J, Kwak J-S, Kim J-H, et al. NAMPT (visfatin), a direct target of hypoxia-inducible factor- $2 \alpha$, is an essential catabolic regulator of osteoarthritis. Ann Rheum Dis 2015;74:595-602. doi:10.1136/annrheumdis-2013-204355.

[65] Wang Y, Wluka AE, Hodge AM, English DR, Giles GG, O'Sullivan R, et al. Effect of fatty acids on bone marrow lesions and knee cartilage in healthy, middle-aged subjects without clinical knee osteoarthritis. Osteoarthr Cartil 2008;16:579-83. doi:10.1016/j.joca.2007.09.007.

[66] Alvarez-Garcia O, Rogers NH, Smith RG, Lotz MK. Palmitate has proapoptotic and proinflammatory effects on articular cartilage and synergizes with interleukin-1. Arthritis \& Rheumatology (Hoboken, NJ) 2014;66:1779-88. doi:10.1002/art.38399.

[67] Fu D, Lu J, Yang S. Oleic/Palmitate Induces Apoptosis in Human Articular Chondrocytes via Upregulation of NOX4 Expression and ROS Production. Ann Clin Lab Sci 2016;46:353-9.

[68] Wu C-L, Jain D, McNeill JN, Little D, Anderson JA, Huebner JL, et al. Dietary fatty acid content regulates wound repair and the pathogenesis of osteoarthritis following joint injury. Ann Rheum Dis 2015;74:2076-83. doi:10.1136/annrheumdis-2014-205601.

[69] Huang ZY, Stabler T, Pei FX, Kraus VB. Both systemic and local lipopolysaccharide (LPS) burden are associated with knee OA severity and inflammation. Osteoarthr Cartil 2016. doi:10.1016/j.joca.2016.05.008.

[70] Collins KH, Paul HA, Reimer RA, Seerattan RA, Hart DA, Herzog W. Relationship between inflammation, the gut microbiota, and metabolic osteoarthritis development: studies in a rat model. Osteoarthr Cartil 2015;23:1989-98. doi:10.1016/j.joca.2015.03.014.

[71] Gu H, Li K, Li X, Yu X, Wang W, Ding L, et al. Oral Resveratrol Prevents Osteoarthritis Progression in C57BL/6J Mice Fed a High-Fat Diet. Nutrients 2016;8:233. doi:10.3390/nu8040233.

[72] Wang Z-M, Chen Y-C, Wang D-P. Resveratrol, a natural antioxidant, protects monosodium iodoacetate-induced osteoarthritic pain in rats. Biomed Pharmacother 2016;83:763-70. doi:10.1016/j.biopha.2016.06.050. 


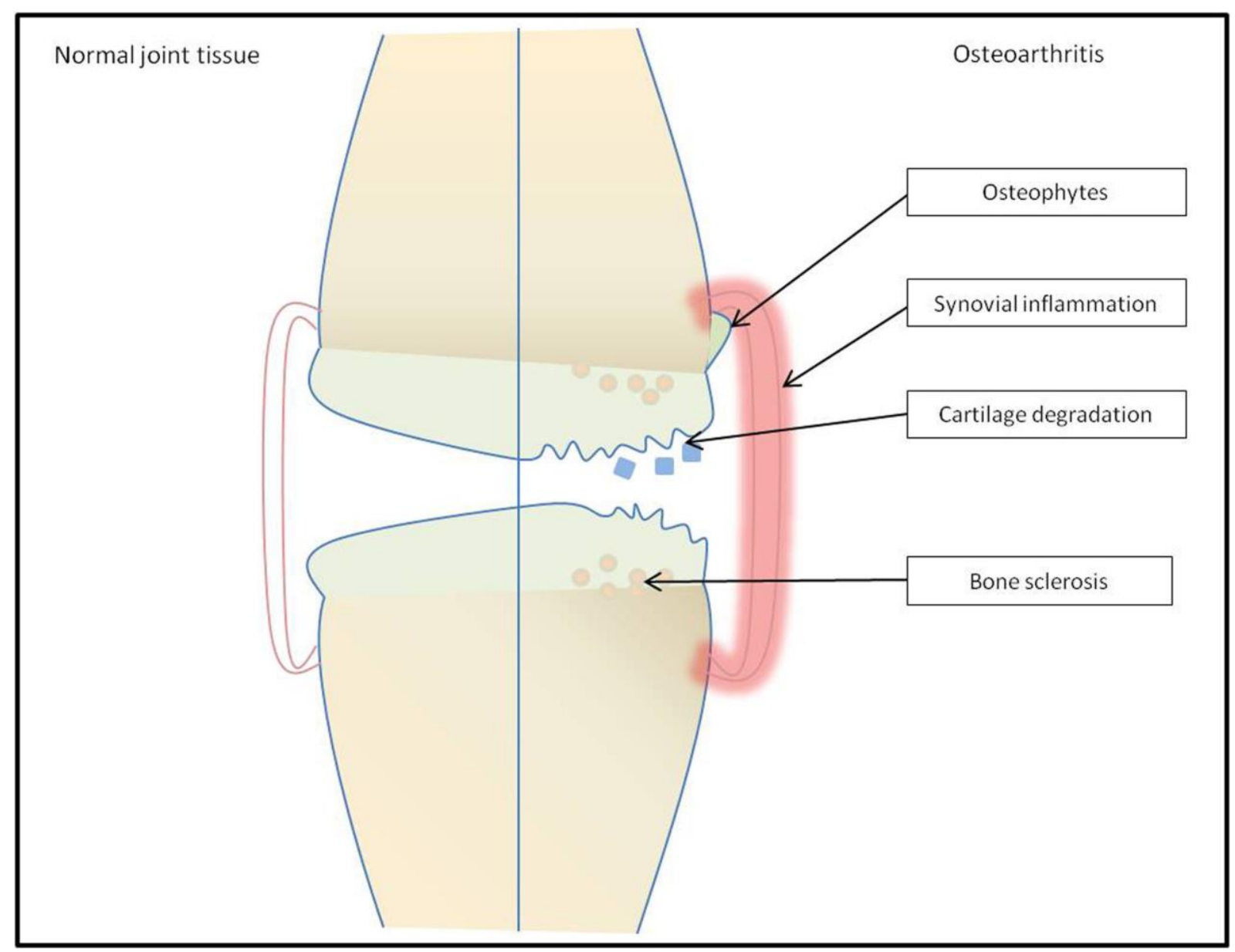

Fig. 1 
Effect of chronic high glucose exposure on chondrocyte

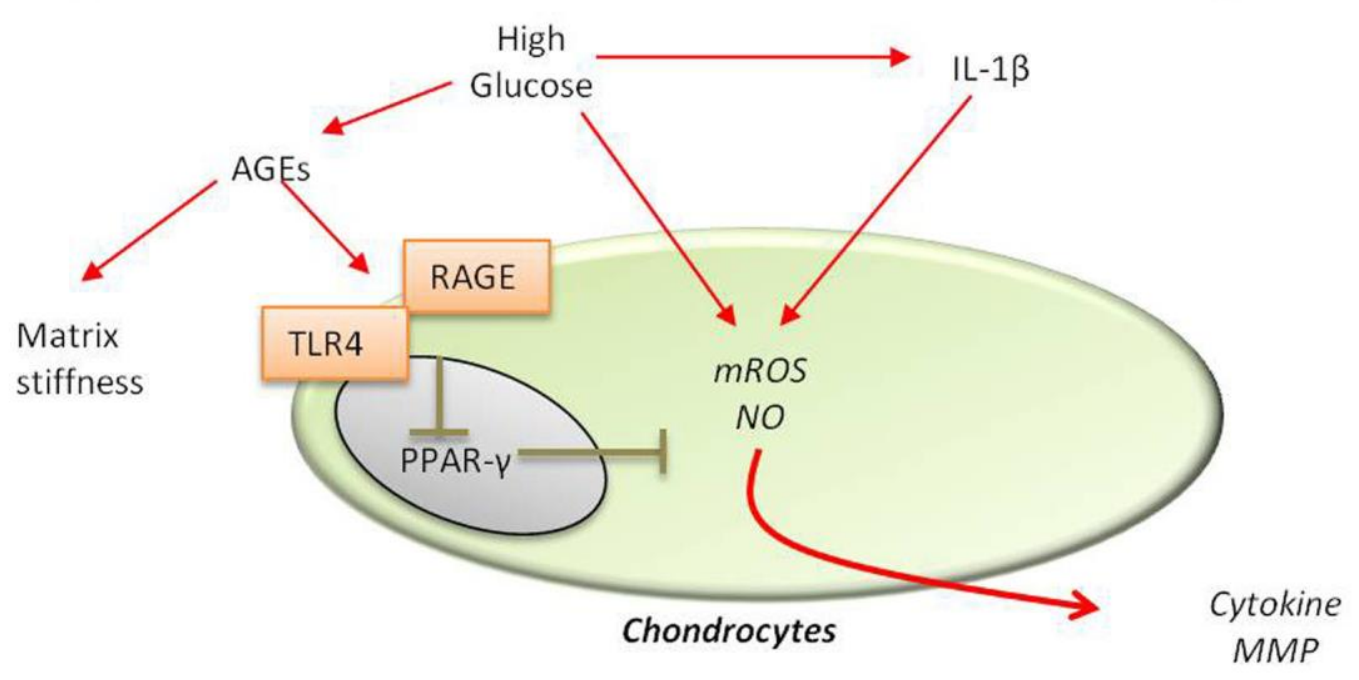

Fig. 2 